E3-2015-94

S. A. Telezhnikov ${ }^{*}$, C. Granja ${ }^{1}$, J. Honzatko ${ }^{2}$, S. Pospisil ${ }^{1}$, I. Tomandl ${ }^{2}$

\title{
PRECISE DETERMINATION
}

\section{OF NEUTRON BINDING ENERGY OF ${ }^{64} \mathrm{Cu}$}

Submitted to "Particles and Nuclei, Letters"

${ }^{1}$ Institute of Experimental and Applied Physics, Czech Technical University, Prague

${ }^{2}$ Nuclear Physics Institute, Řež, Czech Republic

*E-mail: telezhni@nf.jinr.ru 
Тележников С. А. и др.

Прецизионное определение энергии связи нейтрона в ${ }^{64} \mathrm{Cu}$

Энергия связи нейтрона в ${ }^{64} \mathrm{Cu}$ аккуратно измерена при захвате тепловых нейтронов. На высокопоточном нейтронном пучке была использована составная мишень из естественного $\mathrm{Cu}$ и $\mathrm{NaCl}$ в течение длительного времени измерений. Спектр гамма-лучей, испускаемых в $(n, \gamma)$-реакции, измерялся детектором HPGe до получения большой статистики (до $10^{6}$ событий на канал). Определены внутренние свойства HPGe детекторов, которые ограничивают точность энергетической калибровки. Получено значение $B_{n}{ }^{64} \mathrm{Cu}$, равное 7915,867(24) кэВ.

Работа выполнена в Лаборатории нейтронной физики им. И. М. Франка ОИЯИ.

Препринт Объединенного института ядерных исследований. Дубна, 2015

Telezhnikov S. A. et al.

E3-2015-94

Precise Determination of Neutron Binding Energy of ${ }^{64} \mathrm{Cu}$

The neutron binding energy in ${ }^{64} \mathrm{Cu}$ has been accurately measured in thermal neutron capture. A composite target of natural $\mathrm{Cu}$ and $\mathrm{NaCl}$ was used on a high-flux neutron beam using a large measuring time. The $\gamma$-ray spectrum emitted in the $(n, \gamma)$ reaction was measured with a HPGe detector in large statistics (up to $10^{6}$ events per channel). Intrinsic limitations of HPGe detectors, which restrict the accuracy of energy calibration, were determined. The value $B_{n}$ of ${ }^{64} \mathrm{Cu}$ was determined as 7915.867(24) keV.

The investigation has been performed at the Frank Laboratory of Neutron Physics, JINR. 


\section{INTRODUCTION}

Modern intrinsic germanium detector systems enable us to measure $\gamma$ rays with energy up to $10 \mathrm{MeV}$ with precision of $\leqslant 0.1 \mathrm{keV}$ relative to a standard set of energies. In a work devoted to determination of the neutron binding energy in ${ }^{118} \mathrm{Sn}[1], B_{n}$ in ${ }^{64} \mathrm{Cu}$ was determined as well with a value of 7915.52(8) $\mathrm{keV}$ using a HPGe detector. This value differs from the adopted value [2] of 7915.96(11) keV which was obtained in mass measurements [3]. From this discrepancy we decided to carry out a devoted measurement of $B_{n}$ for ${ }^{64} \mathrm{Cu}$ using very large statistics. Furthermore, in order to improve the referential lines in the calibration, we make use of accurate value of $B_{n}$ for ${ }^{36} \mathrm{Cl}$ obtained on high-resolution crystal spectrometer in the $(n, \gamma)$ reaction [4]. Well-established $\gamma$ rays in the reaction ${ }^{35} \mathrm{Cl}(n, \gamma){ }^{36} \mathrm{Cl}$ were used as a standard set of energies. Making use of a pure thermal neutron beam and a long measuring time, we undertook to study neutron capture by copper and chlorine with large statistics. In processing the resulting $\gamma$ spectrum some difficulties must be resolved. The precision of energy measurement became limited not by statistics, but by the characteristics of the HPGe detector. Two main aims were pursued in this work: to achieve energy accuracy as best as possible and to determine the limitations on energy precision in measurements by HPGe detectors.

\section{EXPERIMENTAL}

The experiment was carried out at the light water reactor LWR-15 in Řež near Prague. The facility was described in [5]. It includes a curved neutron guide through which thermal neutrons are transported from the reactor core to the target, a detector system with associated shielding and the electronics. The guide is formed by a mirror-type tube of rectangular cross section, circularly bent in the vertical direction. The internal cross section of guide is $150 \times 4 \mathrm{~mm}^{2}$. The overall length of guide is $5.63 \mathrm{~m}$, the curvature radius being $825 \mathrm{~m}$. At the target position the neutron flux at reactor power of $8 \mathrm{MW}$ is $(2.8 \pm 0.5) \cdot 10^{6} \mathrm{~cm}^{-2} \cdot \mathrm{s}^{-1}$. At the entrance to the target area, dimensions of the incoming neutron beam are additionally reduced to $20 \times 2 \mathrm{~mm}^{2}$ by a ${ }^{6} \mathrm{Li}_{2} \mathrm{CO}_{3}$ plate.

A polyethylene bag with sizes $20 \times 20 \times 2 \mathrm{~mm}^{3}$ with $\mathrm{NaCl}$ and a copper wire with $2 \mathrm{~mm}$ diameter and $20 \mathrm{~mm}$ length were used as a target. Captured $\gamma$ rays were detected by a $28 \%$ HPGe detector (Canberra). Overall time of measurement was about $12 \mathrm{~h}$. The spectrum obtained in this measurement is shown in Fig. 1. 


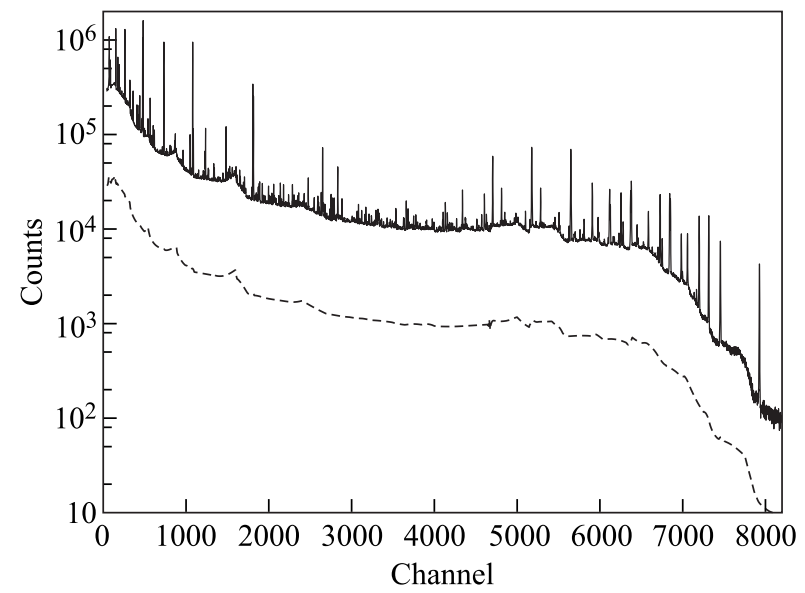

Fig. 1. Spectrum $\mathrm{Cu}, \mathrm{Cl}(n, \gamma)$. Fitting background is shown shifted on one order down
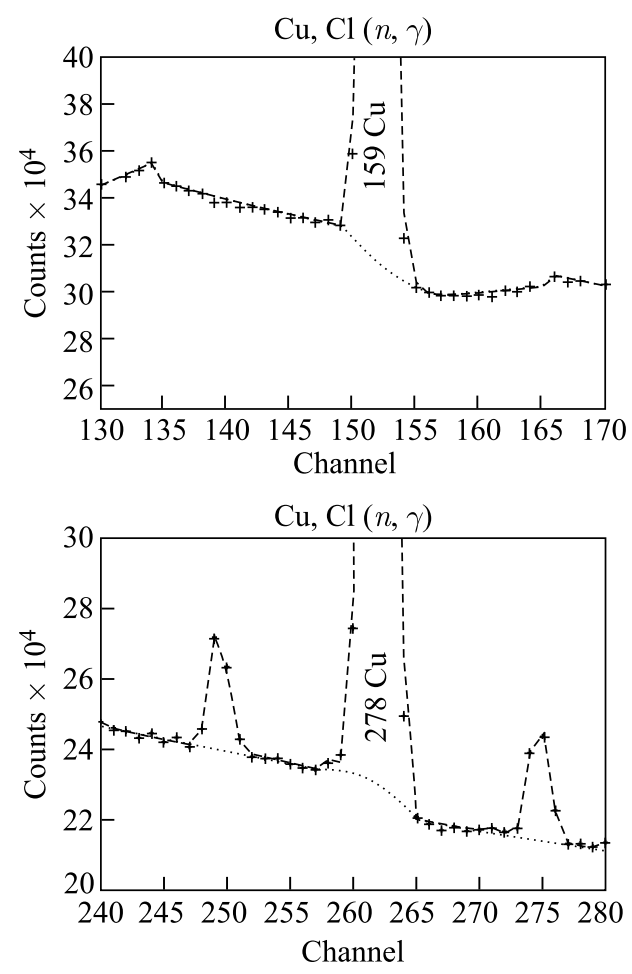

Fig. 2. Peaks with obvious step from scattering $\gamma$ 's 
It can be seen that this spectrum is very complicated not only owing to a great number of peaks, but also because of very complicated feature of background. There are the Compton steps from intense transitions, there are "tails" on the right sides of intense double escape peaks. There is one else source of step on the left side of very strong peaks. This step is attributed to small-angle scattering of the $\gamma$ rays by the target and entrance windows [6]. The peaks at 159 and $278 \mathrm{keV}$ exhibit a marked step in the spectrum as shown in Fig. 2.

\section{PEAK FITTING}

The spectrum was fitted using the FORTRAN computer code SPANAL [7]. Gaussian integrated in limits of each channel is used for form of peak. Gaussian can be spread by exponential for obtaining asymmetric peak. Initial values of the full width on a half of maximum (FWHM) and asymmetry must be given. Code gives the best values of position, area, FWHM and asymmetry of each found peak. Background is described by segments of parabolas which have the same derivative in the points of junction. In view of this, points of break of background (see Fig. 1) must be chosen as the ends of intervals in adjustment.

Initial values of FWHM and asymmetry can be given as polynomial functions and can be fixed, but it was found that on spectrum with large statistics fixation cannot be used, because FWHM has not smooth behavior. It is known that FWHM of annihilation peak is always greater than that of peaks from reaction, besides these secondary $\gamma$ transitions have individual FWHM from the Doppler

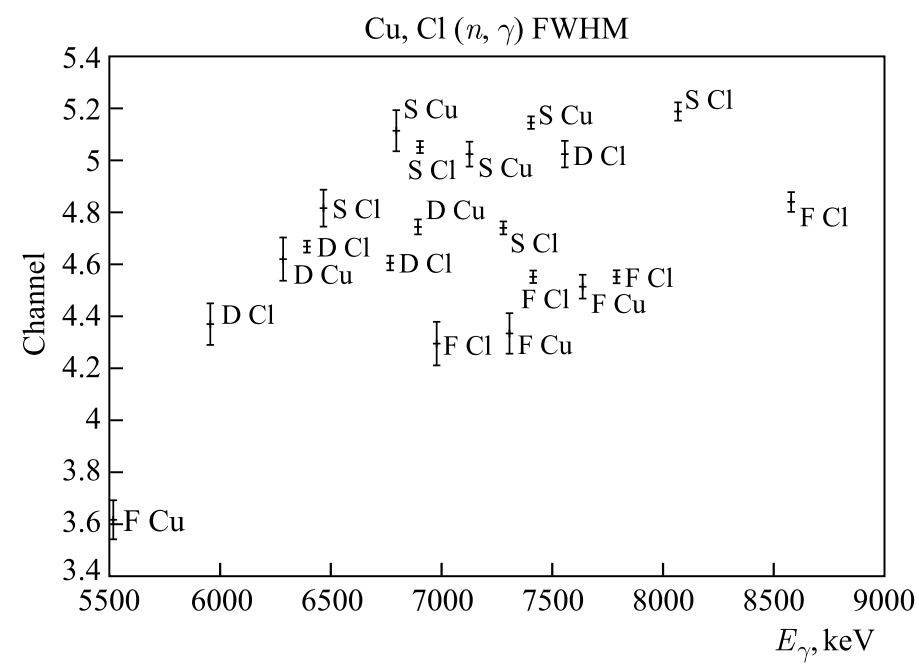

Fig. 3. Dependence of FWHM on $E_{\gamma}$. Single (S), double (D) escape and full energy (F) peaks are indicated 
broadening which is determined by lifetime of level from which this transition decays, and this broadening is used for measure of lifetime of levels [8-10]. Furthermore, single escape (S) peaks and double escape (D) peaks are more broader than full energy (F) peaks at the same region of spectrum. Values of FWHM as a function of energy of $\gamma$ transitions for hard part of spectrum are shown in Fig. 3. (Information about $E_{\gamma}$ from ${ }^{36} \mathrm{Cl}$ was given from [11,12] and about $E_{\gamma}$ from ${ }^{64} \mathrm{Cu}$ - from [2].) At last, in view of big density of peaks on spectrum, probability of superposition of peaks is high. This can increase the value of FWHM.

In fitting of the spectrum, attention was paid to the values of $\chi^{2}$ for each interval. This value was considered as acceptable if it was less than $2 N$, where

Table 1. Comparing of the values of $\chi^{2}$ for the same intervals in dependence on number of peaks found in interval. ( $\mathrm{P}$ - position of peak, $\mathrm{S}$ - area)

\begin{tabular}{|c|c|c|c|c|c|c|}
\hline $\mathrm{P}$ & $\Delta \mathrm{P}$ & $\mathrm{S}$ & $\Delta S$ & FWHM & $\Delta \mathrm{FWHM}$ & $\chi^{2}$ \\
\hline \multicolumn{7}{|c|}{ Interval 257-265 channels } \\
\hline 258.341 & 0.109 & 4331.1 & 728.2 & 1.006 & 0.173 & \multirow[t]{2}{*}{2155.2} \\
\hline 261.715 & 0.001 & 2150308.0 & 1714.9 & 1.489 & 0.002 & \\
\hline 259.833 & 0.105 & 16042.4 & 1027.3 & 2.297 & 0.278 & \multirow{3}{*}{2.3} \\
\hline 261.628 & 0.001 & 1682613.1 & 1589.0 & 1.301 & 0.002 & \\
\hline 262.646 & 0.003 & 436142.4 & 1230.6 & 1.268 & 0.007 & \\
\hline \multicolumn{7}{|c|}{ Interval $480-486$ channels } \\
\hline 482.497 & 0.000 & 3659295.5 & 2020.9 & 1.632 & 0.001 & 5736.8 \\
\hline 478.725 & 0.106 & 581368.1 & 3419.3 & 1.604 & 0.059 & \multirow{3}{*}{0.2} \\
\hline 482.503 & 0.000 & 3408197.3 & 1974.3 & 1.604 & 0.001 & \\
\hline 483.940 & 0.004 & 243463.1 & 932.3 & 1.046 & 0.005 & \\
\hline \multicolumn{7}{|c|}{ Interval 710-738 channels } \\
\hline 714.195 & 0.020 & 30178.0 & 490.5 & 1.748 & 0.055 & \multirow{5}{*}{289.3} \\
\hline 725.797 & 0.091 & 6845.4 & 440.3 & 1.884 & 0.900 & \\
\hline 728.757 & 0.105 & 12882.4 & 580.7 & 2.835 & 0.225 & \\
\hline 731.192 & 0.001 & 993296.3 & 1273.9 & 1.588 & 0.003 & \\
\hline 733.285 & 0.001 & 1944156.4 & 1587.3 & 1.946 & 0.002 & \\
\hline 714.360 & 0.020 & 29036.5 & 479.7 & 1.996 & 0.049 & \multirow{9}{*}{21.4} \\
\hline 720.738 & 0.269 & 2223.9 & 453.8 & 2.077 & 0.780 & \\
\hline 723.536 & 0.175 & 3806.9 & 472.3 & 2.249 & 0.426 & \\
\hline 726.495 & 0.076 & 9212.5 & 488.2 & 2.356 & 0.187 & \\
\hline 728.843 & 0.072 & 5955.4 & 407.8 & 1.408 & 0.180 & \\
\hline 731.304 & 0.001 & 941844.1 & 1201.1 & 1.698 & 0.003 & \\
\hline 733.216 & 0.001 & 1725429.1 & 1557.5 & 1.810 & 0.002 & \\
\hline 734.304 & 0.004 & 270329.0 & 1082.3 & 1.762 & 0.009 & \\
\hline 739.746 & 0.158 & 2471.1 & 392.5 & 1.502 & 0.455 & \\
\hline
\end{tabular}



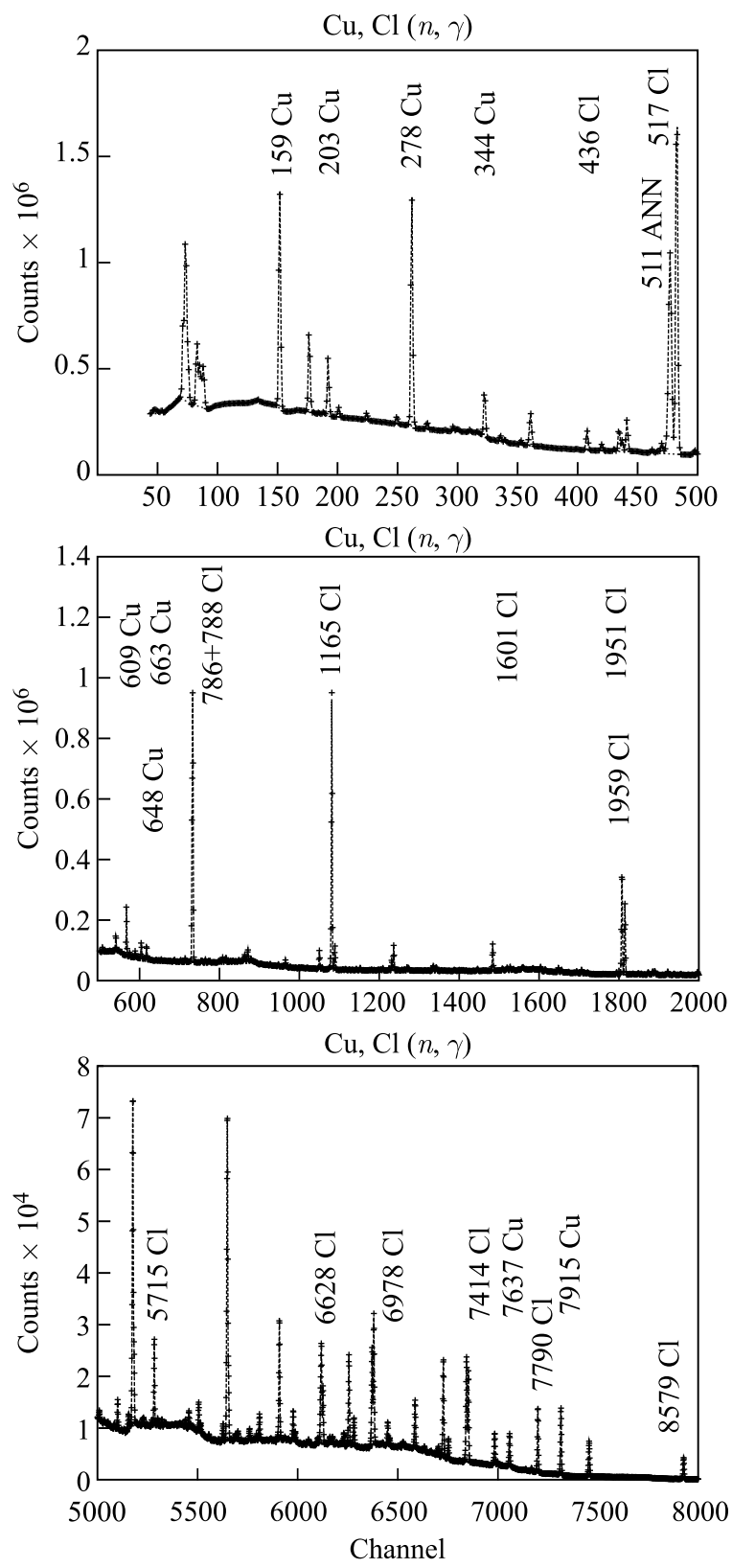

Fig. 4. Three parts of spectrum $\mathrm{Cu}, \mathrm{Cl}(n, \gamma)$ with peaks which were used in calibration procedure 
the degree of freedom $N$ is the number of channels in the interval. From a total of 80 intervals, only 14 have large values of $\chi^{2}$. All intervals in channels 3000-8000 have acceptable $\chi^{2}$. As long as for the determination of the ${ }^{64} \mathrm{Cu}$ binding energy we used positions of some peaks, only six peaks which were used further are from intervals with large values of $\chi^{2}$. It was found that large values of $\chi^{2}$ are in the intervals with peaks which have large statistics and non-Gaussian form. For some intervals, if one big peak is fitted as sum of two or three peaks, the value of $\chi^{2}$ becomes acceptable. Examples of these intervals are shown in Table 1.

It can be ascertained from the results in Table 1 that in spectrum with large statistics (to $10^{6}$ in one channel) fitting with acceptable values of $\chi^{2}$ is possible.
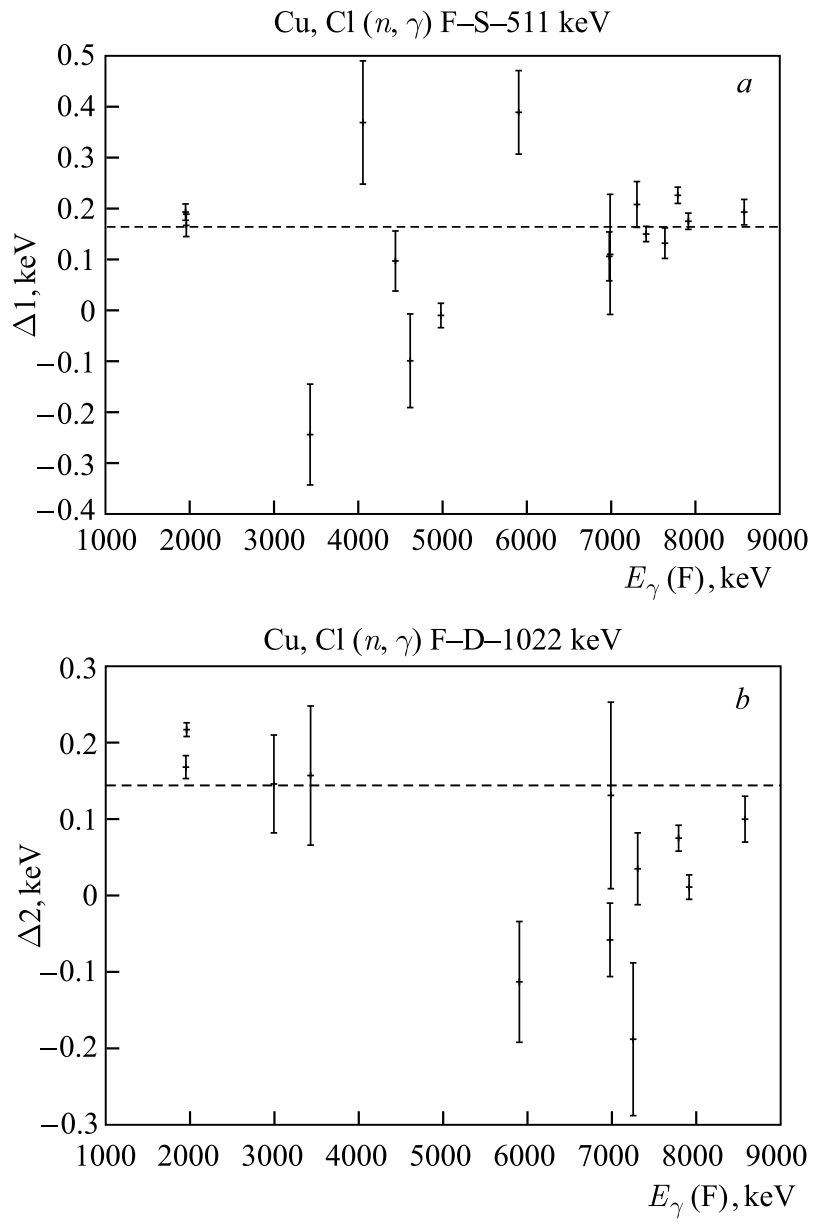

Fig. 5. Dependence of distances $\Delta 1=\left(E_{\mathrm{F}}-E_{\mathrm{S}}-511\right) \mathrm{keV}(a)$ and $\Delta 2=$ $\left(E_{\mathrm{F}}-E_{\mathrm{D}}-1022\right) \mathrm{keV}(b)$ on $E_{\gamma}(\mathrm{F})$. The mean values are shown by lines 
Hence, there is no big differential nonlinearity in amplitude-digital converter and other effects which can disturb statistical properties of the spectrum. Sensitiveness of finding peaks was consciously reduced in intervals in which one or two big peaks must exist. One can hope that in spite of the large value of $\chi^{2}$, positions of centroids of peaks are well.

Three parts of spectrum with peaks which were used for the determination of $B_{n}$ are shown in Fig. 4 .

What precision do we expect to obtain? An accurate calibration in $5-8 \mathrm{MeV}$ region is needed for the determination of $B_{n}$ for ${ }^{64} \mathrm{Cu}$. There are 24 peaks in this region with error of position less than $30 \mathrm{eV}$, but precision of result will depend on how many peaks can be used in calibration procedure. It is known that energies of single escape (S) and double escape (D) peaks are not precisely 511 and $1022 \mathrm{keV}$ less than full energy $(\mathrm{F})$ peaks [13]. We tested these differences in our spectrum and the result is illustrated in Fig. 5 ( $a$ and $b$ ). In this figure the values $\left(E_{\mathrm{F}}-E_{\mathrm{S}}-511\right) \mathrm{keV}$ and $\left(E_{\mathrm{F}}-E_{\mathrm{D}}-1022\right) \mathrm{keV}$ are shown as a function of energy of $\mathrm{F}$ peak. The mean value of $\left(E_{\mathrm{F}}-E_{\mathrm{S}}-511\right) \mathrm{keV}$ is $164 \mathrm{eV}$ and of $\left(E_{\mathrm{F}}-E_{\mathrm{D}}-1022\right) \mathrm{keV}$ is $144 \mathrm{eV}$. In view of this, $\mathrm{S}$ and $\mathrm{D}$ peaks were not used in calibration procedure.

\section{ENERGY CALIBRATION}

Calibration procedure described in [1] was used for the determination of $B_{n}$ for ${ }^{64} \mathrm{Cu}$. This procedure is a mathematically simple minimization function consisting only of terms having as parameters the coefficients of the energy calibration curve (polynomial). A calibration procedure is used for finding a correspondence between the peak positions on a spectrum and the energies. The Least-Squares Method (LSM) is used to determine coefficients of the calibration polynomial. This procedure is intended to determine one value, namely $B_{n}$. In the LSM the best value of one parameter gives minimal value of the chi-square function $Q$ and the second derivative in this point is connected with the standard deviation (SD) of the parameter. In the procedure the value of parameter is changed by steps and each value of function $Q$ is calculated. From interpolation of all these values by parabola the values of $B_{n}$ and $\Delta B_{n}$ are determined. In order to take into account the errors of energies, which are common for some peaks, the Monte Carlo simulation is used in which right connection among all energies is reproduced in each simulation.

Input data for the calibration procedure may be divided into two groups:

(1) The variables, corresponding to some well-known standard energies. Part of them can have independent errors and other part are points, energies of which are connected.

As independent variables in group (1) intense secondary transitions in ${ }^{64} \mathrm{Cu}$ and ${ }^{36} \mathrm{Cl}$ can be used because their energies are known with high precision. 

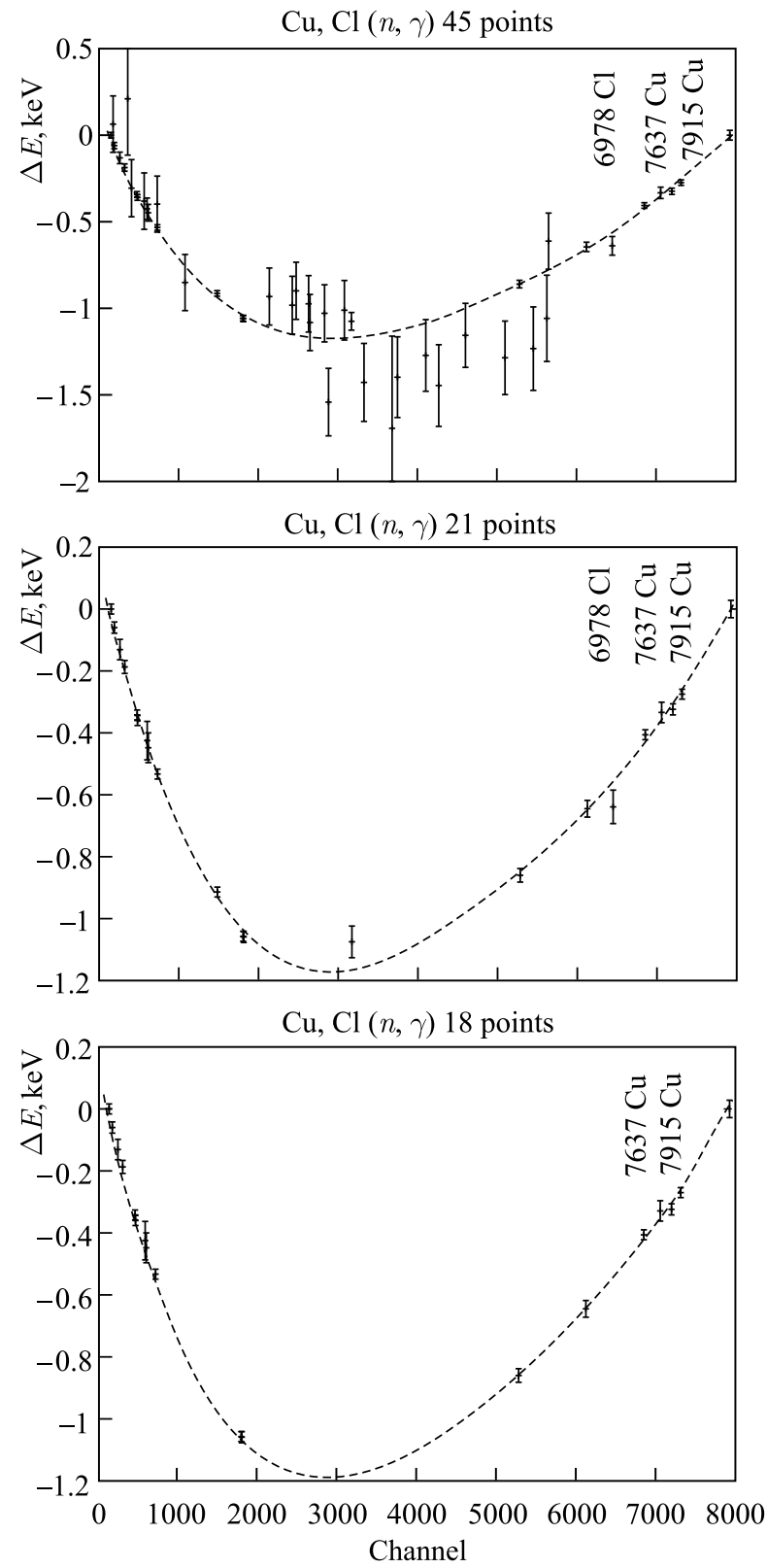

Fig. 6. Deviation of the energy calibration function from a linear function. Three variants of selected points and obtained calibration curves 
Primary transitions in ${ }^{36} \mathrm{Cl}$ are connected to each other through value of $B_{n}$. As $B_{n}$ for ${ }^{36} \mathrm{Cl}$ value $(8579.7945 \pm 0.0048) \mathrm{keV}$ [4] was used.

(2) The variables which present peaks from isotope, $B_{n}$ of which is determined. All energies of these peaks are connected to value of $B_{n}$.

Recoil for hard $\gamma$ rays was taken into account.

One else correction was included in data values: to all transitions with error less than $10 \mathrm{eV}$ value $10 \mathrm{eV}$ was attributed, otherwise there was large value of $\chi^{2}$ for calibration function. This correction concerns the transitions with energy less than $2 \mathrm{MeV}$.

The most complicated part of this work was selection transitions as data for calibration procedure. There is a great number of peaks and if all peaks are included as data in the procedure, good calibration curve cannot be obtained. It is necessary to find some number of peaks with small errors which form a curve. In view of big density of peaks in spectrum, reason for excluding points with big deviation from expected curve almost always can be found since a small contamination to tested peak can visibly shift its position. Three variants of selected points and obtained calibration curves are shown in Fig. 6.

A special system of coordinates is used in calibration procedure and in Fig. 6 - deviation of energy calibration function from a linear function fixed at the first and the last points. It is more convenient to analyze results of calibration in this system. Only two points from ${ }^{63} \mathrm{Cu}(n, \gamma)$ reaction were used in calibration procedure. It seems that points below 3000 channel must not affect $B_{n}$ of ${ }^{64} \mathrm{Cu}$. But there are two reasons to use points from all spectrum: calibration procedure is needed for energy calibration of all spectrum and calibration curve in wide range gives more confidence to obtained results. Results of the determination of $B_{n}$ for ${ }^{64} \mathrm{Cu}$ are shown in Table 2.

The behavior of the values $\chi^{2}$ of fit of seven peaks which give the main influence in $B_{n}$ was tested and results are shown in Table 3. It can be seen that sum of $\chi^{2}$ of the last three peaks is somewhat high, but there are no suspicions that peaks have more complicated form than that used in fitting.

One can compare results from variants (2) and (3) (see Table 2). It is seen that removing of point $6978 \mathrm{keV}$ (near 6500 channel) shifts result on $4 \mathrm{eV}$.

Table 2. Results of the determination of $B_{n}$ for ${ }^{64} \mathrm{Cu}$

\begin{tabular}{|c|c|c|c|c|}
\hline Variant & $N$ points & $\chi^{2} \mathrm{pdf}^{*}$ & $B_{n}, \mathrm{keV}$ & $\Delta B_{n}, \mathrm{keV}$ \\
\hline 1 & 45 & 1.249 & 7915.864 & 0.020 \\
2 & 21 & 1.074 & 7915.863 & 0.020 \\
3 & 18 & 0.527 & 7915.867 & 0.020 \\
4 & 8 & 1.247 & 7915.871 & 0.020 \\
\multicolumn{5}{|l}{ * } \\
* Per degree of freedom.
\end{tabular}


Table 3. The test of fit of seven peaks - sum of $\chi^{2}$ of $N$ channels on intervals (From To)

\begin{tabular}{|c|c|c|c|c|c|c|}
\hline$E_{\gamma}$ & $\mathrm{P}$ & $\Delta \mathrm{P}$ & From & To & $N$ channels & $\sum \chi^{2}$ \\
\hline 5715 & 5284.150 & 0.018 & 5278 & 5288 & 11 & 6.16 \\
6628 & 6126.829 & 0.024 & 6123 & 6131 & 9 & 4.91 \\
7414 & 6852.695 & 0.015 & 6849 & 6858 & 10 & 2.62 \\
7637 & 7058.612 & 0.028 & 7050 & 7063 & 14 & 6.98 \\
7790 & 7200.183 & 0.016 & 7192 & 7205 & 14 & 16.09 \\
7915 & 7315.484 & 0.015 & 7307 & 7320 & 14 & 13.06 \\
8579 & 7927.955 & 0.026 & 7921 & 7932 & 12 & 13.30 \\
\hline
\end{tabular}

Variant (4) in which only points higher than $5700 \mathrm{keV}$ were used gives also shift on $4 \mathrm{eV}$. It is not an error of statistical nature. In view of this, for final result the value $4 \mathrm{eV}$ was added to $20 \mathrm{eV}$ linearly. The final result of this measurement for $B_{n}$ of ${ }^{64} \mathrm{Cu}$ is $(7915.867 \pm 0.024) \mathrm{keV}$.

\section{DISCUSSION}

From spectrum of captured neutrons by copper and chlorine which was measured with large statistics (to $10^{6}$ in one channel) $B_{n}$ of ${ }^{64} \mathrm{Cu}$ was obtained as $(7915.867 \pm 0.024) \mathrm{keV}$. It is evident that precision of energy calibration is limited not by statistics, but characteristics of the HPGe detector. Value $B_{n}$ can be obtained with precision of $10-20 \mathrm{eV}$. For achieving of such a result some problems must be taken into account:

(1) In fitting a spectrum from the HPGe detector the value of FWHM of peaks on spectrum has not smooth behavior in dependence on number of channels.

(2) It is reasonable to use value $10 \mathrm{eV}$ for errors of positions of secondary transitions despite of high statistical precision (lower than $10 \mathrm{eV}$ ).

(3) One needs to be in luck to find some number of peaks with small errors which form a curve in calibration procedure.

One else point can be discussed now in more detail: the use of SE and DE peaks in calibration procedure. In our work these peaks were not used, because their energies do not differ from energies of FE peaks on $m_{0} c^{2}$ and $2 m_{0} c^{2}$, respectively (see Fig. 5): energies of SE and DE peaks are below the expected value on about 170 and $140 \mathrm{eV}$, respectively. There was accurate work [14] in which it has been demonstrated that in measurements of spectra from $(n, \gamma)$ reaction by the Ge detector the spacing between escape peaks is $m_{0} c^{2}$ within an error of $15 \mathrm{eV}$.

On the other hand, the mechanism of obtaining of DE peak energy higher than $\mathrm{E}(\mathrm{FE})-1022 \mathrm{keV}$ was suggested in [13]. It is the annihilation of the positrons on bound electrons. In such a process a small part of the annihilation energy must 
be used to overcome the electron binding energy which results in electron-hole pairs. In addition, the energy of DE peak may further be increased due to the Compton scattering of the annihilation photons to forward angles in the detector active volume.

In our case, we have more simple mechanism to obtain energies of DE and SE peaks, which are lower than expected. Our detector was relatively old and it was used in many experiments on neutron beam and its resolution became worse from radiation damage. This effect can be detected first of all in the peaks from the most higher energy. It is demonstrated in Fig. 3 that SE and DE peaks are wider than FE peaks in the same energy interval. From the bad resolution the mean position of peak is shifted down and we have the energy, which is lower than expected.

Now one may compare value obtained in this work with the previous results. Value of $B_{n}$ for ${ }^{64} \mathrm{Cu}$ in [2] was 7915.96(11) keV and that in [1] was 7915.52(8) keV. Value 7915.867(24) $\mathrm{keV}$ obtained in this work is more close to the value from [2] and on about four standard deviations differs from that in [1].

Preliminary results of this work were presented in [15].

\section{REFERENCES}

1. Borzakov S. B. et al. // Nucl. Instr. Meth. A. 2002. V. 480. P. 696.

2. Balraj Singh // Nucl. Data Sheets. 1996. V.78. P. 395.

3. Audi G., Wapstra A. H. // Nucl. Phys. A. 1993. V.565. P. 1.

4. Dewey M. S., Kessler E. G., Jr., et al. // Phys. Rev. C. 2006. V.73. P. 044303.

5. Honzatko J. et al. // Nucl. Instr. Meth. A. 1996. V.376. P. 434.

6. Stelts M. L., Chrien R.E. // Nucl. Instr. Meth. 1978. V. 155. P. 253.

7. Telezhnikov S. A. JINR Commun. P10-81-358. Dubna, 1981 (in Russian).

8. Borner H. G., Jolie J. // J. Phys. G: Nucl. Part. Phys. 1993. V. 19. P. 217.

9. Ulbig S. et al. // Nucl. Phys. A. 1989. V.505. P. 193.

10. Borner H. G. et al. // Phys. Lett. B. 1988. V.215. P. 45.

11. Krusche B. et al. // Nucl. Phys. A. 1982. V.386. P. 245.

12. Endt P. M. // Nucl. Phys. A. 1998. V.633. P. 1.

13. Hnatowicz $V$. Handbook of Nuclear Data for Neutron Activation Analysis, Vol. 1. Evaluation of Gamma-Ray Spectra. Prague: Nucl. Inf. Center, 1986.

14. Kennet T. J. et al. // Nucl. Instr. Meth. 1983. V.215. P. 159-165.

15. Telezhnikov S. A. et al. // Proc. of the XIV Intern. Seminar on Interaction of Neutrons with Nuclei, Dubna, May 24-27, 2006. Dubna, 2007. P. 296-303.

Received on November 2, 2015. 
Редактор В. В. Булатова

Подписано в печать 08.12.2015.

Формат $60 \times 90 / 16$. Бумага офсетная. Печать офсетная.

Усл. печ. л. 0,87. Уч.-изд. л. 1,24. Тираж 210 экз. Заказ № 58696.

Издательский отдел Объединенного института ядерных исследований 141980, г. Дубна, Московская обл., ул. Жолио-Кюри, 6.

E-mail: publish@jinr.ru www.jinr.ru/publish/ 